\title{
Functional and radiological outcome of Colles fracture treated conservatively with plaster and cast
} Sharma $S^{1}$, Sharma $R^{2}$, Neupane $S^{3}$, Pariyar $A K^{4}$, Singh $R^{1}$

\footnotetext{
${ }^{1}$ Department of Orthopedics, Janaki Medical College and Teaching Hospital, Janakpur, Nepal

${ }^{2}$ Department of Orthopedics, Kathmandu University Teaching Hospital, Kathmandu, Nepal

${ }^{3}$ Department of Pediatrics, Shankarapur Hospital, Kathmandu, Nepal

${ }^{4}$ Department of Anesthesia, Janaki Medical College and Teaching Hospital, Janakpur, Nepal
}

\begin{abstract}
Background and Objectives: Fractures of distal radius are commonly encountered in orthopedic emergency. Various treatment methods are available including closed reduction and immobilization in cast, percutaneous pinning, pins and plaster, external fixation, open reduction and internal fixation with or without bone graft or substitute. There are no clear guidelines to follow. The aim of this study is to compare the radiological and functional outcome of distal radius fracture treated conservatively with cast alone.
\end{abstract}

Material and Methods: Sixty patients suffering from extra articular distal radius fracture were recruited for study. They were all treated conservatively with cast alone. They were followed up for 6 months. The radiological outcome in terms of dorsal angulation, radial length, radial angulation and ulnar variance and functional outcome in terms of Mayo wrist score was assessed.

Results: At 6 months follow up dorsal angulation, radial length, radial angulation and ulnar variance were $-5 \pm 3.20$ degrees, $7.80 \pm 0.77 \mathrm{~mm}, 20.47 \pm 2.29$ degrees and $1.27 \pm 0.77$ respectively. Functionally 20 patients had good outcome, 32 patients had satisfactory outcome and 8 patients had poor outcome in terms of Mayo wristscores.

Conclusion: Conservative management with cast is an effective treatment modality for Frykmans type I and II Colles fracture with satisfactory functional and radiological outcome.

Key Words: Cast. Colles Fracture, Functional and Radiological outcome.

\section{INTRODUCTION}

Fractures of the distal radius are the most common of all skeletal injuries sustained by human beings.(1) Among distal radius fracture, the majority are extra articular fractures. Colles fracture is an extra articular distal radius fracture. There is no consensus regarding the appropriate treatment of this condition or even the anticipated outcome. There is always a debate whether to treat these fractures conservatively or by operative means.

Fractures of the distal radius were considered uncomplicated injuries in the past. Initially, Colles treated these fractures when there was no radiography, aseptic surgery or 
anaesthesia $(1,2)$ and the amount of disability following malunion was accepted. Malunion results in pain, midcarpal instability and posttraumatic arthritis.(3) The degree of disability after a distal radius has been shown to correlate with the amount of residual deformity.(4) Permanent loss of the palmar angle and radial shortening of the distal radius are associated with persistent wrist pain.(5)

A variety of treatment modalities are available for distal radius fractures including close reduction and plaster cast application, close reduction and percutaneous pin application, external fixator using ligamentotaxis and open reduction and internal fixation with plate and screws. $(6,7,8-$ 10)

Many factors determine the choice of treatment such as the patient's age, life style, associated medical conditions, compliance, functional demands, limb dominance, type of fracture, severity and alignment of the fracture, condition of the soft tissue, including any open wound, and concomitant fractures.

Treatment by closed reduction and cast immobilization can be adopted at low cost without admission to hospital. Operative management is expensive and associated with typical surgical risk factors, radiation exposure, and financial expenses. The rationale of this study was to estimate the anatomical and functional outcome of conservative management of Colles fracture as there is dearth of local literature on this topic. This study provides evidence about anatomical and functional outcome of conservative management of Colles fracture.

\section{MATERIAL AND METHODS}

This prospective study was conducted in the Department of Orthopaedics Janaki Medical
College and Teaching Hospital, Janakpur from December 2017 to June 2018.

Cases presenting to Emergency and outpatient department as fractures of distal radius and all cases that fulfill the following criteria were selected - unstable (dorsal angulation $>20$ degrees and radial shortening $>5 \mathrm{~mm}$ ) extra articular distal radius fracture (Frykman type I and II) in all men and women between 40 to 70 years of age. Patients with open fractures, age below 40 years and above 70 years, stable fractures, volar angulated fracture, intra articular fracture, fractures associated with neurovascular and tendon injury, bilateral fractures of wrist, previous distal radius fracture in the contralateral side, inflammatory disease in the opposite wrist such as rheumatoid arthritis, fracture more than 2 weeks duration were excluded from the study.

The approval to conduct this study was obtained from the institutional review board. Informed consent was obtained from patients and confidentiality and anonymity of the data was maintained throughout the study.

Complete history was taken regarding mode of injury and associated comorbidities was identified and recorded. Thorough physical examination was done including all the systems. Injured wrist was examined to identify deformity, neurovascular status and tendon functions were assessed. Contralateral wrist was also examined to rule out previous fractures and involvement of inflammatory disease.

Patients were managed by closed reduction under hematoma block. With patient supine shoulder abducted and elbow flexed, traction was applied to the thumb with counter traction above the elbow by an assistant. If the traction alone was insufficient to correct then surgeon manipulated by compression. Reduction was confirmed clinically and 
radiologically with the help of an image intensifier. When satisfactory reduction defined by radial shortening of $<5 \mathrm{~mm}$ compared with contralateral wrist, radial inclination $\geq 15$ degrees, 15 degrees dorsal tilt to 20 degrees volar tilt) (11) was achieved then below elbow cast was applied with wrist in palmar flexion and ulnar deviation, and forearm in pronation. Check X-ray was taken immediately after reduction. Weekly follow up for first two weeks were done.

Posteroanterior and lateral X-rays were taken. Next follow up was done at $6^{\text {th }}$ week and cast was removed at that time. Active ROM exercise and grip strengthening exercises were started and check X-ray posteroanterior and lateral view was done to assess radiological outcome. Subsequently patient was followed up at $12^{\text {th }}$ week and at $6^{\text {th }}$ month for functional and radiological evaluation.

Radiological/Anatomical evaluation: All measurements were done in X-rays as described by Vander Linden.(12) Values were compared with normal wrist as:

1. Dorsal angulation in degrees

2. Radial length (mm)
3. Radial Inclination in degrees

4. Ulnar variance (mm)

We followed the Mayo wrist scoring system as described by Cooney WP(13) for functional evaluation.

\section{RESULTS}

Sixty patients with extra articular Colles fracture underwent closed manipulation and cast application. Among the 60 patients, there were 40 female and 20 male patients. Their ages ranged from 45 to 65 years. The average age was 54.27 years. The right wrist was involved in 20 patients, whereas the left wrist was involved in 40 patients. There were 32 Frykmann type 1 and 28 Frykmann type 2 distal radius fractures. Falling on an outstretched hand was the commonest mode of injury. The mean pre-reduction dorsal angulation, radial length, radial angulation and ulnar variance were $28.13 \pm 8.40$ degrees, $4.53 \pm 2.03 \mathrm{~mm}, \quad 14.47 \pm 4.01$ degrees, $3.67 \pm 1.54 \mathrm{~mm}$ respectively. After closed reduction and cast application, the mean dorsal angulation, radial length, radial angulation and ulnar variance were -

\begin{tabular}{|} 
Table 1: Variation in dorsal angulation, radial length, radial inclinication and ulnar variance \\
\begin{tabular}{|l|l|l|l|}
\hline Parameters & Mean & SD & Range \\
\hline Pre reduction dorsal angulation & 28.13 & 8.40 & $19.73-36.53$ \\
\hline Pre reduction radial inclination & 4.53 & 2.03 & $2.5-6.56$ \\
\hline Pre reduction radial inclniation & 14.47 & 4.01 & $10.46-18.48$ \\
\hline Pre reduction ulnar variance & 3.67 & 1.54 & $2.13-5.21$ \\
\hline Post reduction dorsal angulation & -11.07 & 4.69 & $-15.76-6.38$ \\
\hline Post reduction radial length & 9.93 & 0.88 & $9.05-10.81$ \\
\hline Post reduction radial inclinatin & 22.13 & 1.88 & $20.25-24.01$ \\
\hline Post reduction ulnar variance & -0.2 & 1.26 & $-1.46-1.24$ \\
\hline Dorsal angulation at 6 months & -5 & 3.20 & $-8.2--1.8$ \\
\hline Radial inclination at 6 months & 7.8 & 0.77 & $7.03-8.57$ \\
\hline Radial inclination at 6 months & 20.47 & 2.29 & $18.18-22.76$ \\
\hline Ulnar variance at 6 months & 1.27 & 0.77 & $0.5-2.04$ \\
\hline
\end{tabular}
\end{tabular}


11.07 \pm 4.69 degrees, $9.93 \pm 0.88 \mathrm{~mm}$, $22.13 \pm 1.88$ degrees, $-0.20 \pm 1.26 \mathrm{~mm}$ respectively. At six months follow up, the mean dorsal angulation, radial length, radial angulation and ulnar variance were $-5 \pm 3.20$ degrees, $7.80 \pm 0.77 \mathrm{~mm}, 20.47 \pm 2.29$ degrees, $1.27 \pm 0.77 \mathrm{~mm}$ respectively. At 6 month, Mayo wrist score grading was good in 20, satisfactory in 32 and poor in 8 cases. There were 8 cases of Reflex Sympathetic Dystrophy (RSD).

\section{Table 2: Mayo wrist score evaluation at different times}

\begin{tabular}{||l|l|l|l|l|}
\hline Evaluation at & Sex & Good & Satisfactory & Poor \\
\hline 6 weeks & Male & & 8 & 12 \\
\cline { 2 - 5 } & Female & & 10 & 30 \\
\hline 6 months & Male & 6 & 12 & 2 \\
\cline { 2 - 5 } & female & 14 & 20 & 6 \\
\hline
\end{tabular}

\section{DISCUSSION}

Fractures of the distal radius are commonly encountered in orthopaedics practice with increasing numbers of low energy fractures in the elderly population.(14) While anatomical reduction can usually be achieved by closed manipulation, there is still no agreement as to the most appropriate way of maintaining reduction in these fractures. Various methods of internal and external stabilization devices have come in to practice over the years to prevent displacement in unstable fractures such as external fixation, percutaneous pinning, intrafocal pinning, pins and plaster, limited open reduction with or without bone grafting or bone substitutes and extensive open reduction and internal fixation.(15)

Our prospective study estimated radiological and functional outcomes of closed reduction and cast immobilization in Frykman type I and type II fractures. The radiological parameters were within the acceptable range. In our study we used Mayo wrist score to assess the functional outcome. Our data showed that 18 patients (30\%) had satisfactory and 42 patients (70\%) had poor results at 6 weeks follow up. At 12 weeks follow up the results improved with 20 patients (33.3\%) good results, 32 patients (53.3\%) satisfactory results and only 8 patients $(13.3 \%)$ showing poor results. This showed that as duration passes the long term functional outcome became better. Eight patients showing poor results could be attributed to RSD.

The reported incidence of RSD varies considerably from $1.4 \%$ to $42 \% \cdot(16,17)$ In a comparative study on 40 patients between plaster group and external fixator group no significant difference was found in symptoms like pain, swelling, deformity and inability to move in both groups.(18) Roumen et al demonstrated that treating distal radiusfracture with external fixator had better radiological outcome, but the functional outcome were no better than the control group.(19)

Grle et al in their prospective study on 122 patients showed excellent early results with conservative management of distal radius fractures.(20) In contrast some studies showed better results with operative treatment of distal radius fracture but they included intraarticular fractures as well.(21)

A meta-analysis of seven studies was done to compare the results between operative and conservative treatment of distal radius fractures. Overall, the radiologic outcome was better in surgically treated cases, however no remarkable difference was found in terms of 
functional results and number of complications.(22)

Young and Rayan demonstrated a satisfactory functional outcome in $88 \%$ of their patients. They treated 25 patients older than 60 years, for distal radius fracture conservatively. There was no significant difference between radiological outcome and the final functional outcome.(23)

The mean age of these fractures in our study was 54.27 years and high occurrence in 50 to 59 years. Study done at Malmo and Bergen(24) showed high occurrence in 60 to 69 years. In the current study $66.6 \%$ of patients were females which is similar to study done at Malmo Sweden (1953) and Bergen (1998).(22)

No case suggestive of median nerve compresssion was observed in our study. Compressive neuropathy of the median, ulnar or radial nerve is reported to occur in 8 to $17 \%$ of distal radius fractures among which median nerve compression is most common.(25)

We did not find any case suggestive of carpal instability or ulnocarpal impingement. We followed our cases only for 6 months but these complications generally appear late. Thus we cannot comment on these due to short follow up duration. No cases of tendon rupture was observed in our study as these are uncommon complications and take place after 6 to 9 months of fracture.(26)

\section{CONCLUSION}

Extraarticular Colles fracture Frykmann type I and II can be treated conservatively with satisfactory functional and radiological outcome. These fractures are more common in elderly female population.

\section{REFERENCES}

1. Colles A. On the Fracture of the Carpal Extremity of the Radius. The New England Journal of Medicine, Surgery and Collateral Branches of Science. 1814;3(4):368-72.

2. Simic PM, Weiland AJ. Fractures of the distal aspect of the radius: changes in treatment over the past two decades. Instructional course lectures. 2003;52:185-95. PubMed PMID: 12690848. Epub 2003/04/15. eng.

3. Miyake $T$, Hashizume $H$, Inoue $H$, Shi $Q$, Nagayama N. Malunited Colles' fracture. Analysis of stress distribution. Journal of hand surgery (Edinburgh, Scotland). 1994 Dec;19(6):737-42. PubMed PMID: 7706877. Epub 1994/12/01. eng.

4. Gartland JJ, Jr., Werley CW. Evaluation of healed Colles' fractures. The Journal of bone and joint surgery American volume. 1951 Oct;33A(4):895-907. PubMed PMID: 14880544. Epub 1951/10/01. eng.

5. Karnezis IA, Panagiotopoulos E, Tyllianakis M, Megas P, Lambiris E. Correlation between radiological parameters and patient-rated wrist dysfunction following fractures of the distal radius. Injury. 2005 Dec;36(12):1435-9. PubMed PMID: 16256994. Epub 2005/11/01.eng.

6. Sivaprakash SU, Reddy RM. Functional outcome of comminuted intra-articular distal radius fractures managed by Ligamentotaxis. Int $\mathrm{J}$ Orthop Sci. 2019;5:75-9.

7. Somesula JB, Venkata Naga MRP. A prospective study of surgical management of distal radius fracture in adult with plate fixation. Int J Orthop Sci. 2017;3:236-40.

8. Bagul R, Yadav K, Rai A, Deo S, Patole V. Comparative study of functional outcome in

9. Colles' fracture treated conservatively by closed reduction and cast and closed reduction, Kirschner wire and cast. J Pharm Biomed Sci. 2016;6:464-8.

10. Anzarut A, Johnson JA, Rowe BH, Lambert RG, Blitz S, Majumdar SR. Radiologic and patientreported functional outcomes in an elderly cohort with conservatively treated distal radius fractures. J Hand Surg Am. 2004;29:1121-7.

11. Grewal R, Perey B, Wilmink M, Stothers K. A randomized prospective study on the treatment of intra-articular distal radius fractures: open reduction and internal fixation with dorsal plating versus mini open

12. reduction, percutaneous fixation, and external fixation. J Hand Surg Am. 2005;30:764-72. 
13. TJ G. surgical correction of malunited fractures of distal radius. J Am Acad Orthop Surg. 1997;5:270.

14. van der Linden W, Ericson R. Colles' fracture. How should its displacement be measured and how should it be immobilized? The Journal of bone and joint surgery American volume. 1981 Oct;63(8):1285-8. PubMed PMID: 7287798. Epub 1981/10/01. eng.

15. Cooney WP, Bussey R, Dobyns JH, Linscheid RL. Difficult wrist fractures. Perilunate fracturedislocations of the wrist. Clinical orthopaedics and related research. $1987 \operatorname{Jan}(214): 136-47$. PubMed PMID: 3791735. Epub 1987/01/01. eng.

16. Jupiter JB. Fractures of the distal end of the radius. The Journal of Bone \& Joint Surgery. 1991 1991-03-01 00:00:00;73(3):461-9.

17. Anzarut A, Johnson JA, Rowe BH, Lambert RG, Blitz S, Majumdar SR. Radiologic and patientreported functional outcomes in an elderly cohort with conservatively treated distal radius fractures. J Hand Surg Am. 2004;29:1121-7.

18. Cooney WP, 3rd, Dobyns JH, Linscheid RL. Complications of Colles' fractures. The Journal of bone and joint surgery American volume. 1980;62(4):613-9. PubMed PMID: 6155380. Epub 1980/01/01. eng..

19. Porter M, Stockley I. Fractures of the distal radius. Intermediate and end results in relation to radiologic parameters. Clinical orthopaedics and related research. 1987 Jul(220):241- 52. PubMed PMID: 3594997. Epub 1987/07/01. eng

20. Kumar K, Laghari MA, Bhutto IA, Lal K. Fracture of Distal Radius Treated by Orthofix v/s Plaster Cast. J Liaquat Uni Med Health Sci. 2014;13:120-4.

21. Roumen RM, Hesp WL, Bruggink ED. Unstable Colles fractures in elderly patients. A randomised trial of external fixator for redisplacement. J Bone Joint Surg Br 1991;73:307-11.

22. Grle M , Miljko M, Grle I , Hodžiæ F, Kapidžiæ T. Early results of the conservative treatment of distal radius fractures immobilization of the wrist in dorsal versus palmar flexion. Med Glas(Zenica).2017;14:236-43.

23. Arora J, Kapoor H, Malik A, Bansal M.Closed reduction and plaster cast,immobilization Vs. external fixation in comminuted intra-articular fractures of distal radius. Indian $\mathbf{J}$ Orthop. 2004;38:113-7.

24. Song J, Yu AX and $\mathrm{Li} \mathrm{ZH}$. Comparison of conservative and operative treatment for distal radius fracture: a meta-analysis of randomized controlled trials. Int $\mathrm{J}$ Clin Exp Med. 2015;8:17023-3

25. Young BT, Rayan GM. Outcome following non operative treatment of displaced distal radius fractures in low demand patients older than 60 years. J Hand Surg 2000;25-A:19-28

26. MO P. From American academy of orhtopaedics, annual meeting. Advances in distal radius fractures management. published in net by orthoteers: 1999.

27. Young BT, Rayan GM. Outcome following nonoperative treatment of displaced distal radius fractures in low-demand patients older than 60 years. The Journal of hand surgery. 2000 Jan;25(1):19-28. PubMed PMID: 10642469. Epub 2000/01/22. eng.

28. Veldman PH, Reynen HM, Arntz IE, Goris RJ. Signs and symptoms of reflex sympathetic dystrophy: prospective study of 829 patients. Lancet (London, England). 1993 Oct 23;342(8878):1012-6. PubMed PMID: 8105263. Epub 1993/10/23. eng.

\section{Correspondence to: Sandeep Sharma} Department of Orthopedics, Janaki Medical College and Teaching Hospital, Janakpur, Nepal Email: sandeep334sharma@gmail.com 